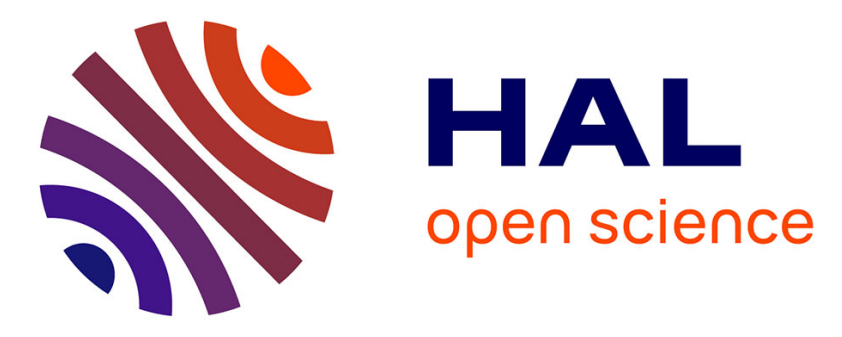

\title{
The psychosocial context of pregnancy smoking \& quitting in the millennium cohort study
}

Kate E Pickett, Richard G Wilkinson, Lauren S Wakschlag

\section{To cite this version:}

Kate E Pickett, Richard G Wilkinson, Lauren S Wakschlag. The psychosocial context of pregnancy smoking \& quitting in the millennium cohort study. Journal of Epidemiology and Community Health, 2009, 63 (6), pp.474-n/a. 10.1136/jech.2008.082594 . hal-00477888

\section{HAL Id: hal-00477888 \\ https://hal.science/hal-00477888}

Submitted on 30 Apr 2010

HAL is a multi-disciplinary open access archive for the deposit and dissemination of scientific research documents, whether they are published or not. The documents may come from teaching and research institutions in France or abroad, or from public or private research centers.
L'archive ouverte pluridisciplinaire HAL, est destinée au dépôt et à la diffusion de documents scientifiques de niveau recherche, publiés ou non, émanant des établissements d'enseignement et de recherche français ou étrangers, des laboratoires publics ou privés. 


\title{
THE PSYCHOSOCIAL CONTEXT OF PREGNANCY SMOKING \& QUITTING IN THE MILLENNIUM COHORT STUDY
}

\author{
Kate E. Pickett, ${ }^{1}$ Richard G. Wilkinson, ${ }^{2}$ Lauren S. Wakschlag ${ }^{3}$ \\ ${ }^{1}$ Senior Lecturer, Department of Health Sciences, University of York, UK \\ ${ }^{2}$ Professor, Division of Epidemiology and Community Health, University of Nottingham \\ Medical School, UK \\ ${ }^{2}$ Associate Professor, Institute for Juvenile Research, Department of Psychiatry, University \\ of Illinois at Chicago, Illinois, USA
}

Please address correspondence to:

Dr. Kate E. Pickett

Department of Health Sciences

University of York

Seebohm Rowntree Building, Room A/TB/220

Heslington,

York, YO10 5DD

UK

Email: kp6@york.ac.uk

Current word count: 3271

Word count for abstract: 221 


\begin{abstract}
Background. Although pregnancy is a time in which women have increased motivation to quit smoking, approximately half of female smokers persist in smoking throughout their pregnancies. Persistent pregnancy smokers are known to be more nicotine dependent and to have greater socio-demographic disadvantage. Less is known about the psychosocial context of persistent pregnancy smokers and factors that distinguish them from pregnancy quitters.
\end{abstract}

Methods. We conducted a cross-sectional study within the UK Millennium Cohort Study. Participants were 18,225 women, including $13.3 \%$ quitters, $12 \%$ light smokers and $8 \%$ heavy smokers. Data were collected when the infants were 9 months old. Maternal psychosocial problems were assessed in three domains: interpersonal, adaptive functioning and health-related behaviours.

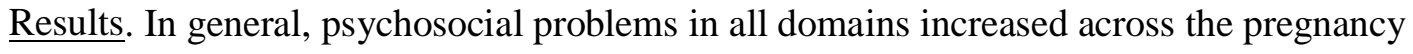
smoking continuum (non-smoker, quitter, light smoker, heavy smoker). All three psychosocial domains added incremental utility to prediction of pregnancy smoking status, after adjustment for socio-demographic risk.

Conclusion. Problems in multiple psychosocial domains systematically distinguish women along a pregnancy smoking gradient, with heavy smokers having the most problematic psychosocial context. This sub-group of pregnant smokers is unlikely to be able to benefit from usual-care antenatal cessation interventions, which rely on women's capacity for selfinitiation, self-control and social resources. Consideration should be given to tiered interventions that provide more intensive and targeted interventions to pregnant women unable to quit with usual care. 


\section{INTRODUCTION}

"Behavior change is difficult". ${ }^{1}$ More than forty years of research in health education and health promotion suggests that it may be easier for people to adopt new habits than to give up existing behaviours, ${ }^{2}$ that interventions that work in research settings are rarely as successful in practice, ${ }^{34}$ and that short-term positive changes are hard to maintain. ${ }^{5-7}$ These difficulties are often thought to reflect ways in which health-related behaviours are embedded in individual, family, community and societal contexts.

In the UK in $2005,32 \%$ of women smoked cigarettes in the year before they become pregnant. ${ }^{8}$ Studies suggest that around $80 \%$ of pregnant smokers would like to quit, ${ }^{9}$ and only around $6 \%$ have strong intentions of continuing to smoke. ${ }^{10}$ Around half of the women who smoke in the year before pregnancy quit just before or during pregnancy, but $17 \%$ of women admit to continuing to smoke throughout pregnancy - exposing around 120,000 infants each year. ${ }^{11}$ Between 2005-2006, the NHS Stop Smoking Services recorded 17,917 pregnant women setting a quit date; at 4 weeks post-quit date, just over half (54\%) had stopped smoking, quit rates at the end of pregnancy were not recorded. ${ }^{8}$ Meta-analysis of 48 trials suggests that smoking cessation interventions are effective for pregnant women, but the absolute effect is small (6 more women quitting per 100 smoking women assigned to interventions). ${ }^{12}$ Relapse rates for women who quit during pregnancy are high, $66.7-80 \%$ are smoking again within a year. ${ }^{1314}$

Although women want to quit and feel guilty about their smoking, many feel powerless to change their behaviour. ${ }^{15}$ The government White Paper "Smoking Kills" set a target for 2010 to reduce smoking in pregnancy to $15 \% .{ }^{16}$ However, the former Health Development Agency noted that little is known about how to improve smoking cessation rates among disadvantaged pregnant women and that interventions are less effective in reallife settings than in trials; ${ }^{17}$ others have noted the difficulty in improving quit rates among 
heavier smokers ${ }^{18}$ and those who persist into the third trimester. ${ }^{19}$

It is known that, compared to persistent pregnancy smoking, women who don't smoke, or who manage to quit smoking are more likely to be older, employed, and better

educated. ${ }^{20-23}$ They are less likely to be depressed ${ }^{22}{ }^{24}$ or highly-stressed, ${ }^{25}$ to be a single or co-habiting parent, ${ }^{2627}$ to have a smoking partner ${ }^{28} 29$ or an abusive partner, ${ }^{30}$ to have low social support, ${ }^{31}$ or to live in a working-class neighbourhood. ${ }^{32} 33$ However, a broader understanding of the individual psychosocial context in which pregnancy smoking is embedded may be helpful for both the development of more effective smoking cessation programmes and for further research into the risks associated with smoking in pregnancy. Based on a small study $(n=96)$ of predominantly white, working class women in Chicago we have previously proposed a framework which places persistent smoking in pregnancy within a constellation of maternal psychosocial problems. ${ }^{34} 3536$ Whilst these studies provided some evidence of the highly complex nexus of psychosocial problems in which women smoke during pregnancy, in this study we apply this framework to the population-based Millennium Cohort Study, with the aim of testing whether there are systematic differences in psychosocial problems across multiple domains that differentiate women who never smoke and women who manage to quit from those who continue to smoke.

\section{METHODS}

$\underline{\text { Study design, setting and participants }}$

The Millennium Cohort Study (MCS) is a large prospective study of infants born in 2000-2001 in the UK. In this study we use data primarily from the first wave of data collection, which took place when the infants were around 9 months old and includes 18,818 infants in 18,552 families. Families living in the smaller constituent countries of the UK and in areas (electoral wards) with high levels of childhood deprivation and high proportions of 
ethnic minorities were over-sampled. Infants born on eligible dates in eligible areas were selected from the Child Benefit register (Child Benefit is a universal benefit payable from birth).

The response rate for the eligible sample was $82 \%$; non-respondents were more likely to be without a fixed residence, living in ethnic minority areas in England, or living in advantaged areas in Northern Ireland. ${ }^{37}$ Full details on the Millennium Cohort Study have been published previously ${ }^{38}$ and are supplied in documentation deposited with the data at the UK Data Archive. This study excludes families with multiple births $(n=256)$, families where someone other than the natural mother was the respondent $(n=57)$ and families with insufficient information to classify maternal smoking during pregnancy $(n=4)$, giving an analytic sample of 18,225 mothers.

\section{Measurement of maternal smoking during pregnancy}

Retrospective information was collected on smoking during pregnancy by women's self-report. Mothers were asked how many cigarettes per day they smoked prior to pregnancy, whether they had changed the amount they smoked during pregnancy, and the number of cigarettes they smoked per day after the change. We classified mothers as (1) never having smoked during pregnancy, (2) quit smoking during pregnancy, (3) persistent light smokers during pregnancy (less than 10 cigarettes per day) and (4) persistent heavy smokers during pregnancy (10+ cigarettes per day).

\section{Measurement of maternal demographic and socioeconomic factors}

Women's age was measured in years and the number of children in the household counted. Marital status was defined as married, cohabiting or solo. Three measures of socioeconomic status were examined: income-related poverty was defined as household income 
below $60 \%$ of the median; mother's educational attainment was dichotomized into two groups - those with academic qualifications of GCSE grades A-C and above, versus those with lower, overseas or no academic qualifications. Mothers' social class was categorized according to the National Statistics Socio-Economic Classification (NS-SEC), ${ }^{39}$ dichotomized into working class occupations (routine and semi-routine occupations) versus all others. Mother's ethnicity was self-reported and classified into six groups.

Measurement of domains of maternal psychosocial problems

Based on previous theoretical work, ${ }^{34}$ we focused on 3 domains of maternal psychosocial problems:

\section{Interpersonal problems}

Four measures were considered to be indicators of problematic relationships in the mother's family of origin: (a) having left home before age 17 (other than for boarding school), (b) family breakdown (parents separated or never lived together); and never seeing their (c) mother or (d) father, if living.

Four measures were considered to be indicators of problematic relationships with peers and others: (a) having spent no time with friends in the past week or having no friends, (b) having nobody to share feelings with, (c) not being able to talk to other parents about their experiences, and (d) feeling their neighbours were unfriendly.

Four measures of problematic intimate/family relationships included: (a) low scores on a shortened version of the Golombok Rust Inventory of Marital State, which measures closeness, communication and satisfaction with one's partner; ${ }^{40}$ (b) mother's report of intimate partner violence ( $2 \%$ of the sample refused to answer this question); (c) mothers' reporting that they felt very impatient and or annoyed/irritated with the baby very frequently or almost all the time and (d) history of having lived with multiple, non-marital partners. 


\section{Problems in maternal adaptive functioning}

Maternal well-being was assessed in three domains: (a) Psychological distress measured by a modified Malaise Inventory, ${ }^{41}$ which included items asking if mothers suddenly become scared for no reason, are worried all the time, or are keyed up and jittery; (b) Low self-esteem measured by a modified Rosenberg Self-Esteem Scale; (c) Low sense of control.

Problems with parenting were indicated by women stating that they lacked competence and confidence in parenting.

Problems in daily functioning included whether or not mothers had: no bank account in the past year; financial difficulties; problems with reading, writing or maths that interfered with day-to-day activities, such as paying bills and writing letters; any period of being homeless since the baby was born; and no working telephone (including mobile phones).

\section{Health-risk behaviours}

Pregnancy-related health-risk behaviours included whether the pregnancy was unplanned, late entry into antenatal care (> 12 weeks gestation), short inter-pregnancy interval (pregnant again at the time of interview), and not having attempted breast feeding. Problems related to substance use included heavy alcohol consumption ( $>2$ drinks per day) and two behaviours measured only in the second wave of the Millennium Cohort study, which took place when the offspring were 3 years old - occasional and regular use of illegal drugs (data available for $n=12,918$ ), and alcohol dependence (available $n=14,003$ ), measured by the CAGE screening assessment. ${ }^{42}$ 


\section{$\underline{\text { Statistical analysis }}$}

All analyses were carried out using survey weights and commands in Stata version10, to correct for the complex sampling design of the study. Sample characteristics are described using means and proportions, with differences tested by Wald tests and chi-square tests, respectively. In all tables, we present un-weighted counts and weighted percentages.

For predictive analyses of the effects of maternal psychosocial characteristics on smoking during pregnancy, we created indices for domains and sub-domains of problems. The domain of interpersonal problems included sub-domains of problems in family of origin, problems with peers and others, and problems in intimate relationships and current family. The domain of adaptive functioning included sub-domains of problems of maternal wellbeing, parenting problems and problems with daily functioning. The health-related behaviour domain included sub-domains of pregnancy-related health behaviour problems and substance use. (We did not include drug use and alcohol abuse in the substance use subdomain as it was available for a much smaller sample) All domain and sub-domain scores were sums of problems within each category. These were regressed on smoking status in survey-weighted multinomial logistic regression models, independently and in sets. In a final model we included all three domains of problems and adjusted for maternal sociodemographic characteristics to test the incremental utility of the psychosocial domains for prediction. 
Table 1: Characteristics of mothers by maternal smoking status during pregnancy

\begin{tabular}{|c|c|c|c|c|}
\hline & $\begin{array}{c}\text { Never smoked } \\
\qquad \begin{array}{c}\mathrm{N}=11,706 \\
65.7 \%\end{array}\end{array}$ & $\begin{array}{l}\text { Quit smoking } \\
\qquad \begin{array}{c}\mathrm{N}=2,319 \\
13.3 \%\end{array}\end{array}$ & $\begin{array}{c}\text { Light smoker } \\
\begin{array}{c}\mathrm{N}=2,390 \\
12.2 \%\end{array}\end{array}$ & $\begin{array}{c}\text { Heavy smoker } \\
\qquad \begin{array}{c}\mathrm{N}=1810 \\
8.8 \%\end{array}\end{array}$ \\
\hline & Mean $(S E)$ & Mean (SE) & Mean $(S E)$ & Mean (SE) \\
\hline Mother's age (years)* & $30.0(0.12)$ & $26.9(0.19)$ & $26.3(0.16)$ & $26.7(0.16)$ \\
\hline Children in household* & $1.9(0.01)$ & $1.6(0.02)$ & $1.9(0.02)$ & $2.3(0.03)$ \\
\hline & $\%$ & $\%$ & $\%$ & $\%$ \\
\hline $\begin{array}{l}\text { Marital status* } \\
\text { Married } \\
\text { Cohabiting } \\
\text { Solo }\end{array}$ & $\begin{array}{l}79.4 \\
47.8 \\
37.9\end{array}$ & $\begin{array}{c}9.4 \\
19.6 \\
19.1\end{array}$ & $\begin{array}{c}6.9 \\
18.8 \\
23.8\end{array}$ & $\begin{array}{c}4.3 \\
13.8 \\
19.2\end{array}$ \\
\hline $\begin{array}{l}\text { Household income-related poverty* } \\
\text { Above } 60 \% \text { median poverty indicator } \\
\text { Below } 60 \% \text { median poverty indicator }\end{array}$ & $\begin{array}{l}72.7 \\
46.8 \\
\end{array}$ & $\begin{array}{l}13.2 \\
13.9 \\
\end{array}$ & $\begin{array}{c}9.0 \\
20.9 \\
\end{array}$ & $\begin{array}{c}5.0 \\
18.4 \\
\end{array}$ \\
\hline $\begin{array}{l}\text { Mother's educational qualifications* } \\
\text { GCSE grades A-C and above } \\
\text { Less than GCSE A-C, overseas and no qualifications }\end{array}$ & $\begin{array}{l}71.7 \\
50.1\end{array}$ & $\begin{array}{l}13.4 \\
12.9\end{array}$ & $\begin{array}{c}9.8 \\
18.7\end{array}$ & $\begin{array}{c}5.1 \\
18.3\end{array}$ \\
\hline $\begin{array}{l}\text { Mother's social class* } \\
\text { Non-working class } \\
\text { Working class }\end{array}$ & $\begin{array}{l}74.8 \\
50.6\end{array}$ & $\begin{array}{l}12.7 \\
15.6\end{array}$ & $\begin{array}{c}8.2 \\
18.7\end{array}$ & $\begin{array}{c}4.2 \\
15.1\end{array}$ \\
\hline $\begin{array}{l}\text { Mother's ethnic group* } \\
\text { White } \\
\text { Mixed } \\
\text { Indian } \\
\text { Pakistani/Bangladeshi } \\
\text { Black/Black British } \\
\text { Other }\end{array}$ & $\begin{array}{l}63.2 \\
54.7 \\
92.8 \\
96.1 \\
79.8 \\
84.0\end{array}$ & $\begin{array}{c}14.1 \\
19.7 \\
5.1 \\
1.1 \\
9.7 \\
10.0\end{array}$ & $\begin{array}{c}13.1 \\
18.5 \\
1.7 \\
0.2 \\
8.6 \\
4.3\end{array}$ & $\begin{array}{l}9.6 \\
7.0 \\
0.4 \\
0.6 \\
1.9 \\
1.7\end{array}$ \\
\hline
\end{tabular}

*Differences statistically significant at $\mathrm{p}<0.0001$ 


\section{RESULTS}

Table 1 shows the demographic and socioeconomic characteristics of mothers by categories of smoking during pregnancy. More than a third (34.3\%) of mothers smoked for some time during pregnancy, and around a third of these quit smoking, $91 \%$ of them during the first trimester (data not shown). Almost one in ten women smoked heavily throughout the pregnancy. All socio-demographic factors were significantly related to smoking in pregnancy: for all measures light and heavy persistent smokers are worse off than never smokers and women who quit. On some measures, women who quit are better off than never smokers, on others they have an intermediate status between never smokers and light smokers.

Women who smoked at any time during pregnancy were younger than non-smokers despite this, heavy smokers had a higher number of children in the household. Married women had very low rates of smoking throughout pregnancy (6.9\% light smokers, $4.3 \%$ heavy smokers), women who were cohabiting had higher rates, and smoking was much more prevalent among single mothers, almost one in five of whom was a heavy smoker. Among women living in poverty, around one in five smoked throughout pregnancy, whereas among women not living in poverty less than one in ten smoked continuously. Among women with low educational qualifications, $18 \%$ smoked throughout pregnancy, among more educated women, $8.2 \%$ were light smokers and less than 5\% were heavy smokers. Women of white, mixed and black ethnicity had notably higher rates of smoking in pregnancy than women of Indian or Pakistani/Bangladeshi ethnicity.

Figure 1 shows that smokers exhibit a higher prevalence of problematic interpersonal relationships within their family of origin, with peers and neighbours, and in their intimate relationships, compared to quitters and non-smokers.. Women who quit smoking have more problems than women who never smoked, except for social support from friends. Women 
who quit and light smokers were not significantly less likely to never see their mother than never smokers, but heavy smokers were twice as likely not to.

The same pattern is seen for smoking and adaptive functioning in Figure 2. Smokers have a higher prevalence of problems in adaptive functioning, compared to women who quit and those who didn't smoke. The expected gradient from fewest problems among never smokers to most problems among heavy smokers was observed, and statistically significant, with three exceptions. Women who quit did not have significantly more problems with parenting competence than women who never smoked, and problems with reading and maths were less prevalent among women who quit versus women who never smoked. Homelessness was most prevalent among light smokers, who were 3.75 times as likely to have had a period of homelessness as women who didn't smoke during pregnancy.

Associations between smoking in pregnancy and mothers' health-risk behaviours are shown in Figure 3. All pregnancy-related behaviours have the expected gradient in relation to smoking, although late entry to antenatal care is not significantly worse in quitters compared to never smokers and short inter-pregnancy interval is only significantly more likely among heavy smokers. For heavy alcohol use, we found that women who quit smoking during pregnancy had the highest prevalence, indeed they were significantly more likely to be heavy alcohol users than heavy smokers $(\mathrm{OR}=1.55, \mathrm{p}<0.001)$, consistent with our previous work ${ }^{34}$. For alcohol abuse, both women who quit and heavy smokers have a higher likelihood of dependency than never smokers and light smokers. Smoking is significantly related to the regular and occasional use of other, illegal, substances.

Table 2 shows associations for counts of problems within each domain and subdomain of maternal psychosocial characteristics. These relative risks represent the increased risk of quitting or persistent smoking associated with each additional problem within the domain, compared to never-smokers. A supplemental Table 2S, available online, presents 
comparable relative risks for light and heavy continuous smokers, compared to women who quit. Thus if a woman has only one problem with interpersonal relationships, she is $67 \%$ more likely to be a persistent heavy smoker than to never smoke ( $R R=1.67,95 \%$ CI:1.57,1.78). However, if she has four interpersonal problems, she is 7.8 times more likely to be a heavy smoker $\left(1.67^{4}\right)$.

Table 3 shows that all three domains of problems add incremental prediction to maternal smoking status. These associations remained significant after adjustment for maternal socio-demographic characteristics. Holding socio-demographic characteristics constant, a woman with one problem in each domain would be $50 \%$ more likely to smoke and then quit than to never smoke $(1.19 \times 1.10 \times 1.18), 67 \%$ more likely to be a persistent light smoker $(1.19 \times 1.15 \times 1.22)$ and $100 \%$ more likely to be heavy smoker $(1.23 \times 1.17 \mathrm{x}$ 1.43). If a woman had two problems in each domain, she would be 2.25 times more likely to smoke but quit, 2.79 times more likely to be a light smoker, and more than 4 times as likely to smoke heavily throughout pregnancy. A supplemental Table 3S, available online, presents comparable analyses for light and heavy continuous smokers, with women who quit as the reference group. All three domains of problems are independently significantly more common among heavy smokers, compared to quitters and light smokers are significantly more likely to have problems of adaptive functioning and health and health-related behaviour problems. However, after the inclusion of socio-demographic characteristics, the only statistically significant difference between quitters and smokers is that heavy smokers have significantly more health and health-related behaviour problems. This suggests that differences in psychosocial context among women who are smoking at the start of pregnancy are less pronounced than between them and women who never smoke. 
Table 2: Unadjusted relative risks* for quitting smoking and persistent smoking, vs. never smoking during pregnancy, in relation to maternal psychosocial characteristics

\begin{tabular}{|l|c|c|c|c|c|c|}
\hline & \multicolumn{2}{|c|}{ Quit smoking } & \multicolumn{2}{|c|}{ Light smoker } & \multicolumn{2}{|c|}{ Heavy smoker } \\
\hline Maternal Psychosocial Characteristics & RR & $95 \%$ CI & RR & $95 \%$ CI & RR & $95 \%$ CI \\
\hline Interpersonal problems & $\mathbf{1 . 2 7}$ & $\mathbf{1 . 2 1 , 1 . 3 3}$ & $\mathbf{1 . 4 2}$ & $\mathbf{1 . 3 6 , 1 . 4 9}$ & $\mathbf{1 . 6 7}$ & $\mathbf{1 . 5 7 , 1 . 7 8}$ \\
Problematic relationships in family of origin & 1.49 & $1.40,1.59$ & 1.71 & $1.60,1.82$ & 2.16 & $2.00,2.33$ \\
Problematic relationships with peers/ others & 1.03 & $0.95,1.12$ & 1.28 & $1.18,1.38$ & 1.51 & $1.40,1.63$ \\
Problematic intimatelfamily relationships & 1.44 & $1.32,1.57$ & 1.64 & $1.50,1.80$ & 1.90 & $1.72,2.10$ \\
\hline Problems of adaptive functioning & $\mathbf{1 . 3 8}$ & $\mathbf{1 . 3 1 , 1 . 4 5}$ & $\mathbf{1 . 6 5}$ & $\mathbf{1 . 5 8 , 1 . 7 2}$ & $\mathbf{1 . 8 8}$ & $\mathbf{1 . 7 9 , 1 . 9 7}$ \\
Problems of maternal well-being & 1.32 & $1.22,1.44$ & 1.56 & $1.45,1.68$ & 1.82 & $1.67,1.99$ \\
Problems with parenting & 1.23 & $1.05,1.43$ & 1.91 & $1.66,2.20$ & 2.71 & $2.36,3.11$ \\
Problems with daily functioning* & 1.48 & $1.38,1.59$ & 2.05 & $1.93,2.17$ & 2.49 & $2.32,2.67$ \\
\hline Health-related behaviour problems & $\mathbf{1 . 2 9}$ & $\mathbf{1 . 2 4 , 1 . 3 4}$ & $\mathbf{1 . 5 8}$ & $\mathbf{1 . 5 1 , 1 . 6 5}$ & $\mathbf{2 . 0 5}$ & $\mathbf{1 . 9 6 , 2 . 1 5}$ \\
Pregnancy-related health behaviour problems & 1.45 & $1.32,1.50$ & 1.99 & $1.86,2.12$ & 2.43 & $2.26,2.62$ \\
Problems related to substance use & 1.38 & $1.26,1.51$ & 1.48 & $1.34,1.64$ & 2.72 & $2.45,3.04$ \\
\hline
\end{tabular}

* Relative risks are for counts of problems and represent the increased risk associated with one additional problem, if a mother has $2+$ problems the relative risk should be exponentiated by the number of problems 

Table 3: Adjusted relative risks for quitting smoking and persistent smoking, vs. never smoking during pregnancy, in relation to maternal psychosocial characteristics

\begin{tabular}{|l|c|c|c|c|c|c|}
\hline & \multicolumn{3}{|c|}{ Adjusted for other psychosocial domains } & \multicolumn{2}{c|}{ Adjusted for other psychosocial domains + socio- } \\
demographic factors* \\
\hline Maternal psychosocial domains & Quit smoking & Light smoking & Heavy smoking & Quit smoking & Light smoking & Heavy smoking \\
\hline & RR (95\% CI) & RR (95\% CI) & RR (95\% CI) & RR (95\% CI) & RR (95\% CI) & RR (95\% CI) \\
\hline Interpersonal problems & $1.16(1.09,1.24)$ & $1.23(1.14,1.32)$ & $1.30(1.19,1.43)$ & $1.16(1.08,1.24)$ & $1.19(1.10,1.29)$ & $1.23(1.10,1.36)$ \\
\hline Problems of adaptive functioning & $1.21(1.12,1.31)$ & $1.32(1.22,1.43)$ & $1.40(1.27,1.54)$ & $1.10(1.00,1.21)$ & $1.15(1.06,1.26)$ & $1.17(1.04,1.31)$ \\
\hline Health and health-related behaviour & $1.23(1.15,1.31)$ & $1.36(1.26,1.47)$ & $1.69(1.55,1.84)$ & $1.18(1.09,1.27)$ & $1.22(1.13,1.31)$ & $1.43(1.30,1.57)$ \\
problems & & & & & &
\end{tabular}

* Socio-demographic factors included mother's age, number of children in household, marital status, household poverty, mother's education, household social class, ethnicity 


\section{Discussion}

Previous research has shown that women who continue to smoke during pregnancy tend to smoke more heavily, have started smoking earlier and are more addicted, than those who quit, ${ }^{43}$ and have a more adverse socio-demographic profile, but the psychosocial context of this behaviour has not been examined in-depth in population-based samples.

Three studies within the Chicago-based Family Health and Development Project (FHDP) have shown that women who quit and women who continue to smoke are systematically different across multiple domains of psychosocial problems, including interpersonal problems, adaptive functioning and other health-risk behaviours, ${ }^{34}$ as well as conduct problems. ${ }^{35}$ In addition to prediction of pregnancy smoking status, a problematic psychosocial context also had incremental utility for predicting differences in pregnancy smoking intensity, with greater stress and fewer resources associated with heavier smoking. ${ }^{36}$ Whilst these studies provided some evidence of the highly complex nexus of psychosocial problems in which women continue to smoking during pregnancy, the FHDP sample was small $(\mathrm{n}=96)$, predominantly white and working class. Our study rigorously tests the relative contribution of these multiple domains and confirms that these patterns are also salient in a contemporary, population-based UK sample and that they are linked to pregnancy smoking status independently of socio-demographic factors.

A potential limitation of our study is the reliance on retrospective, self-report of smoking in pregnancy, although the recall period was relatively brief ( 9 months). Further,

non-disclosure of smoking is less likely in observational studies not focused on smoking, ${ }^{44} 45$ such as the MCS, than in studies focused on smoking cessation ${ }^{46}$ or conducted in clinical settings. Prospective self-report and biochemical measures are also not feasible before women learn they are pregnant - which is the point at which they are most likely to quit. Detailed assessment of pregnancy smoking patterns is likely to reduce non-disclosure rates; 
for example, the use of multiple choice questions versus a simple yes/no question can increase disclosure by $40 \% .^{47}$

Our findings highlight the challenge of tobacco control policies and interventions among pregnant women and suggest why persistent smoking in pregnancy has been such an intractable problem. This challenge is highlighted by the failure of even the most innovative and intensive antenatal interventions to effect change among persistent heavy smokers. ${ }^{48} 49$ On the other hand, many women are motivated to quit during pregnancy, which presents a window of opportunity for cessation and preventing health risks to the foetus. ${ }^{50}$ The problematic psychosocial context of persistent pregnancy smoking reported here is consistent with those characteristics identified as a barrier to treatment success for adult smokers, including psychiatric co-morbidities, other substance use and stressful life circumstances. ${ }^{50}$ This suggests suggest that interventions that go beyond the pregnant woman's smoking behaviour to take the psychosocial context of pregnancy smoking into account are likely to be more effective.

"Usual care" interventions in antenatal care are typically brief (around 3 minutes) and/or rely on self-help materials based on the '5As' (Ask, Advise, Assess, Assist, Arrange), ${ }^{50}$ although the UK National Health Service currently offers a dedicated smoking cessation service for pregnant smokers, with multi-session and one-to-one behavioural support; as well as nicotine replacement therapy and a helpline. These minimal interventions rely heavily on women having the psychological and social resources to independently implement behavioural strategies such as planning something nice to do every day, thinking of other ways to occupy their hands, practicing new ways to relax, and getting family and friend to help. As we have found, persistent smokers, particularly those who smoke heavily, are less likely to have supportive relationships with others, and have lower self-esteem and sense of control and fewer resources (social, financial and psychological) on which to draw. They are less likely to 
be able to implement such strategies to begin with and less likely to be able to sustain them. A recent meta-analysis suggests that even relatively minimal psychosocial interventions (e.g., addition of bimonthly phone calls for support) increase abstinence rates (from $7.6 \%$ for usual care to $13.3 \%$ ) but effectiveness remains low. ${ }^{50}$ Our findings suggest that a tiered intervention strategy (usual care at first antenatal visit, targeted intervention for women still smoking at next visit) with more intensive intervention methods (e.g. provision of financial incentives, ${ }^{51}$ pharmacological treatments, ${ }^{52}$ motivational interviewing or cognitive behavioural techniques to promote general stress reduction and coping skills) may enhance effectiveness. In the United States, the Public Health Service Clinical Practice Guideline recommends the use of motivational counselling techniques to increase smoking cessation, but makes the recommendation on only " $\mathrm{B}$ " grade level of evidence; the body of evidence in this case consisting of diverse modes of counselling; with variable results and an insufficient number of acceptable studies for meta-analysis. ${ }^{50}$ However, programmes which teach general decision-making and problem-solving skills, media literacy, emotional coping and social skills to adolescents, not specifically targeted at smoking, have been successful in reducing and preventing substance use in adolescents. ${ }^{53}$ Interventions which fail to address the complex psychosocial context of smoking that we demonstrate here are likely to continue with only moderate success.

Our findings are also directly relevant to research on risks of smoking in pregnancy for children's development and behaviour. Smoking during pregnancy is the greatest modifiable risk factor for pregnancy-related morbidity and mortality. Although the risks of smoking during pregnancy for perinatal outcomes, such as foetal growth restriction, shorter gestation and perinatal mortality are clear, ${ }^{545}$ the causal impact of foetal exposure to cigarette smoke on long-term outcomes, including behaviour and cognition remains uncertain. ${ }^{56-58}$ Determining whether or not in utero exposure is causally related to such 
outcomes or whether smoking in pregnancy is a marker for intergenerational processes associated with both the tendency to smoke and to have offspring with behavioural and cognitive problems will depend on adequate characterization of maternal psychosocial characteristics of women who never smoke, quit or continue to smoke in pregnancy ${ }^{58}$. Studies which fail to measure and control for a full-range of psychosocial factors will provide biased over-estimates of risk. The same bias is likely to affect all studies of smoking and health outcomes where stress may play a role in disease onset. 


\section{What this paper adds}

\section{What is already known on this subject}

- In the UK, around one-third of women smoke cigarettes in the year before they become pregnant, and although most would like to quit, only half of these women quit just before or during pregnancy: $17 \%$ of women are persistent smokers throughout exposing around 120,000 infants each year.

- Smoking cessation interventions for pregnant women are of limited effectiveness.

- Socio-economic and demographic factors linked to persistent pregnancy smoking are well-known but less is known about the psychosocial complexities that distinguish persistent smokers from those who quit and those who never smoke

\section{What this study adds}

- Problems in interpersonal relationships, adaptive functioning and other health-risk behaviours are systematically worse among heavy smokers.

- Heavy smokers are unlikely to benefit from usual-care antenatal smoking cessation programmes, and need more intensive and targeted interventions.

- Epidemiological studies of the effect of smoking on any stress-related health outcome will likely provide biased over-estimates unless a full-range of psychosocial factors are controlled. 


\section{FIGURE LEGENDS}

Figure 1: Prevalence of problems in interpersonal relationships, by smoking in pregnancy status, in the Millennium Cohort Study

Figure 2: Prevalence of problems in adaptive functioning, by smoking in pregnancy status, in the Millennium Cohort Study

Figure 3: Prevalence of health problems and health-related behaviour problems, by smoking in pregnancy status, in the Millennium Cohort Study 


\section{Acknowledgements}

Kate Pickett is supported by a UK NIHR (National Institute of Health Research) Career

Scientist Award. Support for Drs Pickett and Wakschlag during the writing of this paper was also provided by grant 1R01DA15223 from the US National Institute for Drug Abuse. Lauren Wakschlag is also supported by The Waldon and Jean Young Shaw Foundation and the Children's Brain Research Foundation. No sponsor had a role in the design or conduct of this study. The authors also thank: the ESRC Data Archive at Essex University for providing the Millennium Cohort Study data, Jayne Hutchinson for assistance with the estimates from the second wave of the study, and Robin Mermelstein for advice on the effectiveness of motivational interviewing.

\section{Copyright statement}

The Corresponding Author has the right to grant on behalf of all authors and does grant on behalf of all authors, an exclusive licence (or non-exclusive for government employees) on a worldwide basis to the BMJ Publishing Group Ltd and its Licensees to permit this article (if accepted) to be published in Journal of Epidemiology and Community Health and any other BMJPGL products to exploit all subsidiary rights, as set out in our licence (http://jech.bmj.com/ifora/licence.pdf).

\section{Competing interest statement}

All authors declare that the answer to the questions on your competing interest form are all No and therefore have nothing to declare.

\section{Contributors}


All authors participated in the design and writing of the study. KEP conducted the analyses and is guarantor for the paper.

Ethics approval was not required for this secondary analysis of anonymized data. 


\section{References}

1. Institute of Medicine. Health and Behavior: The Interplay of Biological, Behavioral, and Societal Influences. Washington, D.C.: National Academy Press, 2001.

2. Bouton ME. A learning theory perspective on lapse, relapse, and the maintenance of behavior change. Health Psychol 2000;19(1 Suppl):57-63.

3. Glasgow RE, Bull SS, Gillette C, Klesges LM, Dzewaltowski DA. Behavior change intervention research in healthcare settings: a review of recent reports with emphasis on external validity. Am J Prev Med 2002;23(1):62-9.

4. Oldenburg BF, Sallis JF, Ffrench ML, Owen N. Health promotion research and the diffusion and institutionalization of interventions. Health Educ. Res. 1999;14(1):121130.

5. Jeffery RW, Drewnowski A, Epstein LH, Stunkard AJ, Wilson GT, Wing RR, et al. Longterm maintenance of weight loss: current status. Health Psychol 2000;19(1 Suppl):516.

6. Marcus BH, Dubbert PM, Forsyth LH, McKenzie TL, Stone EJ, Dunn AL, et al. Physical activity behavior change: issues in adoption and maintenance. Health Psychol 2000;19(1 Suppl):32-41.

7. Ockene JK, Emmons KM, Mermelstein RJ, Perkins KA, Bonollo DS, Voorhees CC, et al. Relapse and maintenance issues for smoking cessation. Health Psychol 2000;19(1 Suppl):17-31.

8. Office for National Statistics and NHS. Statistics on smoking: England, 2006. London: The Information Centre, NHS, 2006.

9. British Medical Association. Smoking and reproductive life: The impact of smoking on sexual, reproductive and child health. London: BMA, 2004. 
10. Ershoff DH, Solomon LJ, Dolan-Mullen P. Predictors of intentions to stop smoking early in prenatal care. Tob Control 2000;9 Suppl 3:III41-5.

11. Bolling K, Grant C, Hamlyn B, Thornton A. Infant Feeding Survey 2005. London: The Information Centre, NHS, 2007.

12. Lumley J, Oliver SS, Chamberlain C, Oakley L. Interventions for promoting smoking cessation during pregnancy. Cochrane Database Syst Rev 2004(4):CD001055.

13. Hajek P, West R, Lee A, Foulds J, Owen L, Eiser JR, et al. Randomized controlled trial of a midwife-delivered brief smoking cessation intervention in pregnancy. Addiction 2001;96(3):485-94.

14. Orleans CT, Barker DC, Kaufman NJ, Marks JF. Helping pregnant smokers quit: Meeting the challenge in the next decade. Tobacco Control 2000;9(Suppl.III):iii6-11.

15. Copeland L. An exploration of the problems faced by young women living in disadvantaged circumstances if they want to give up smoking: can more be done at general practice level? Fam Pract 2003;20(4):393-400.

16. Great Britain Department of Health. Smoking kills: A White Paper on tobacco. London: The Stationery Office, 1998.

17. Bull J, Mulvihill C, Quigley R. Prevention of low birth weight: assessing the effectiveness of smoking cessation and nutritional interventions. London:: Health Development Agency, 2003.

18. Ershoff DH, Quinn VP, Boyd NR, Stern J, Gregory M, Wirtschafter D. The Kaiser Permanente prenatal smoking cessation trial: when more isn't better, what is enough? Tob Control 2000;9 Suppl 3:III60.

19. DiClemente CC, Dolan-Mullen P, Windsor RA. The process of pregnancy smoking cessation: implications for interventions. Tob Control 2000;9 Suppl 3:III16-21. 
20. Graham H, Der G. Patterns and predictors of smoking cessation among British women. Health Promot Int 1999;14:231-9.

21. Agrawal A, Knopik VS, Pergadia ML, Waldron M, Bucholz KK, Martin NG, et al. Correlates of cigarette smoking during pregnancy and its genetic and environmental overlap with nicotine dependence. Nicotine Tob Res 2008;10(4):567-78.

22. Hanna EZ, Faden VB, Dufour MC. The motivational correlates of drinking, smoking, and illicit drug use during pregnancy. J Subst Abuse 1994;6(2):155-67.

23. Martin LT, McNamara M, Milot A, Bloch M, Hair EC, Halle T. Correlates of smoking before, during, and after pregnancy. Am J Health Behav 2008;32(3):272-82.

24. Pritchard CW. Depression and smoking in pregnancy in Scotland. J Epidemiol Community Health 1994;48(4):377-82.

25. Paarlberg KM, Vingerhoets AJJM, Passchier J, Heinen AGJJ, Dekker GA, van Geijn HP. Smoking status in pregnancy is associated with daily stressors and low well-being. Psychology and Health 1999;14:87-96.

26. Thue E, Schei B, Jacobsen G. Psychosocial factors and heavy smoking during pregnancy among parous Scandinavian women. Scand J Prim Health Care 1995;13(3):182-7.

27. Kiernan K, Pickett KE. Marital status disparities in maternal smoking during pregnancy, breastfeeding and maternal depression. Soc Sci Med 2006;63:335-346.

28. Wakefield M, Gillies P, Graham H, Madeley R, Symonds M. Characteristics associated with smoking cessation during pregnancy among working class women. Addiction 1993;88(10):1423-30.

29. Appleton PL, Pharoah POD. Partner smoking behavior change is associated with women's smoking reduction and cessation during pregnancy. British Journal of Health Psychology 1998;3:361-374. 
30. McFarlane J, Parker B, Soeken K. Physical abuse, smoking, and substance use during pregnancy: prevalence, interrelationships, and effects on birth weight. J Obstet Gynecol Neonatal Nurs 1996;25(4):313-20.

31. Dejin-Karlsson E, Hanson BS, Ostergren PO, Ranstam J, Isacsson SO, Sjoberg NO. Psychosocial resources and persistent smoking in early pregnancy--a population study of women in their first pregnancy in Sweden. J Epidemiol Community Health 1996;50(1):33-9.

32. Pickett KE, Wakschlag LS, Rathouz PJ, Leventhal BL, Abrams B. The working-class context of pregnancy smoking. Health Place 2002;8(3):167-75.

33. Sellstrom E, Arnoldsson G, Bremberg S, Hjern A. The neighbourhood they live in: does it matter to women's smoking habits during pregnancy? Health Place 2008;14(2):15566.

34. Wakschlag LS, Pickett KE, Middlecamp MK, Walton LL, Tenzer P, Leventhal BL. Pregnant smokers who quit, pregnant smokers who don't: does history of problem behavior make a difference? Soc Sci Med 2003;56(12):2449-60.

35. Kodl MM, Wakschlag LS. Does a childhood history of externalizing problems predict smoking during pregnancy? Addict Behav 2004;29(2):273-9.

36. Weaver KE, Wakschlag LS, Campbell R, Mermelstein R. Pregnancy smoking in context: The influence of multiple levels of stress. Annals of Behavioral Medicine In press.

37. Dex S, Joshi H, editors. Children of the 21st century: From birth to nine months. Bristol: Policy Press, 2005.

38. Smith K, Joshi H. The Millennium Cohort Study. Popul Trends 2002(107):30-4.

39. Office for National Statistics. The National Statistics Socio-economic Classification: User Manual. London: Palgrave McMillan, 2005. 
40. Rust J, Bennun I, Crowe M, Golombok S. The GRIMS: a psychometric instrument for the assessment of marital discord. Journal of Family Therapy 1990;12:45-57.

41. Rutter M, Tizard J, Whitmore K. Education, health and behaviour. London: Longmans, 1970.

42. Ewing J. Detecting alcoholism: The CAGE questionnaire. Journal of the American Medical Association 1984;252:1905-1907.

43. Gilman SE, Breslau J, Subramanian SV, Hitsman B, Koenen KC. Social factors, psychopathology, and maternal smoking during pregnancy. Am J Public Health 2008;98(3):448-53.

44. Klebanoff MA, Levine RJ, Clemens JD, DerSimonian R, Wilkins DG. Serum cotinine concentration and self-reported smoking during pregnancy. Am J Epidemiol 1998;148(3):259-62.

45. Pickett KE, Rathouz PJ, Kasza K, Wakschlag LS, Wright R. Self-reported smoking, cotinine levels, and patterns of smoking in pregnancy. Paediatr Perinat Epidemiol 2005;19(5):368-76.

46. Russell T, Crawford M, Woodby L. Measurements for active cigarette smoke exposure in prevalence and cessation studies: why simply asking pregnant women isn't enough. Nicotine Tob Res 2004;6 Suppl 2:S141-51.

47. Mullen PD, Carbonari JP, Tabak ER, Glenday MC. Improving disclosure of smoking by pregnant women. Am J Obstet Gynecol 1991;165(2):409-13.

48. Melvin C, Gaffney C. Treating nicotine use and dependence of pregnant and parenting smokers: an update. Nicotine Tob Res 2004;6 Suppl 2:S107-24.

49. Ershoff D, Ashford TH, Goldenberg R. Helping pregnant women quit smoking: an overview. Nicotine Tob Res 2004;6 Suppl 2:S101-5. 
50. Fiore MC, Jaen CR, al e. Treating Tobacco Use and Dependence: 2008 Update.

Rockville, MD: Department of Health and Human Services (US), Public Health Service, Agency for Health Care Policy and Research, 2008.

51. Donatelle R, Hudson D, Dobie S, Goodall A, Hunsberger M, Oswald K. Incentives in smoking cessation: status of the field and implications for research and practice with pregnant smokers. Nicotine Tob Res 2004;6 Suppl 2:S163-79.

52. Benowitz N, Dempsey D. Pharmacotherapy for smoking cessation during pregnancy. Nicotine Tob Res 2004;6 Suppl 2:S189-202.

53. Botvin GJ, Griffin KW. Life skills training: empirical findings and future directions. $J$. Prim. Prev. 2004;25:211-232.

54. Shea AK, Steiner M. Cigarette smoking during pregnancy. Nicotine Tob Res 2008;10(2):267-78.

55. Salihu HM, Wilson RE. Epidemiology of prenatal smoking and perinatal outcomes. Early Hum Dev 2007;83(11):713-20.

56. Button TM, Maughan B, McGuffin P. The relationship of maternal smoking to psychological problems in the offspring. Early Hum Dev 2007;83(11):727-32.

57. Rogers JM. Tobacco and pregnancy: overview of exposures and effects. Birth Defects Res C Embryo Today 2008;84(1):1-15.

58. Wakschlag LS, Pickett KE, Cook E, Jr., Benowitz NL, Leventhal BL. Maternal smoking during pregnancy and severe antisocial behavior in offspring: a review. Am J Public Health 2002;92(6):966-74. 


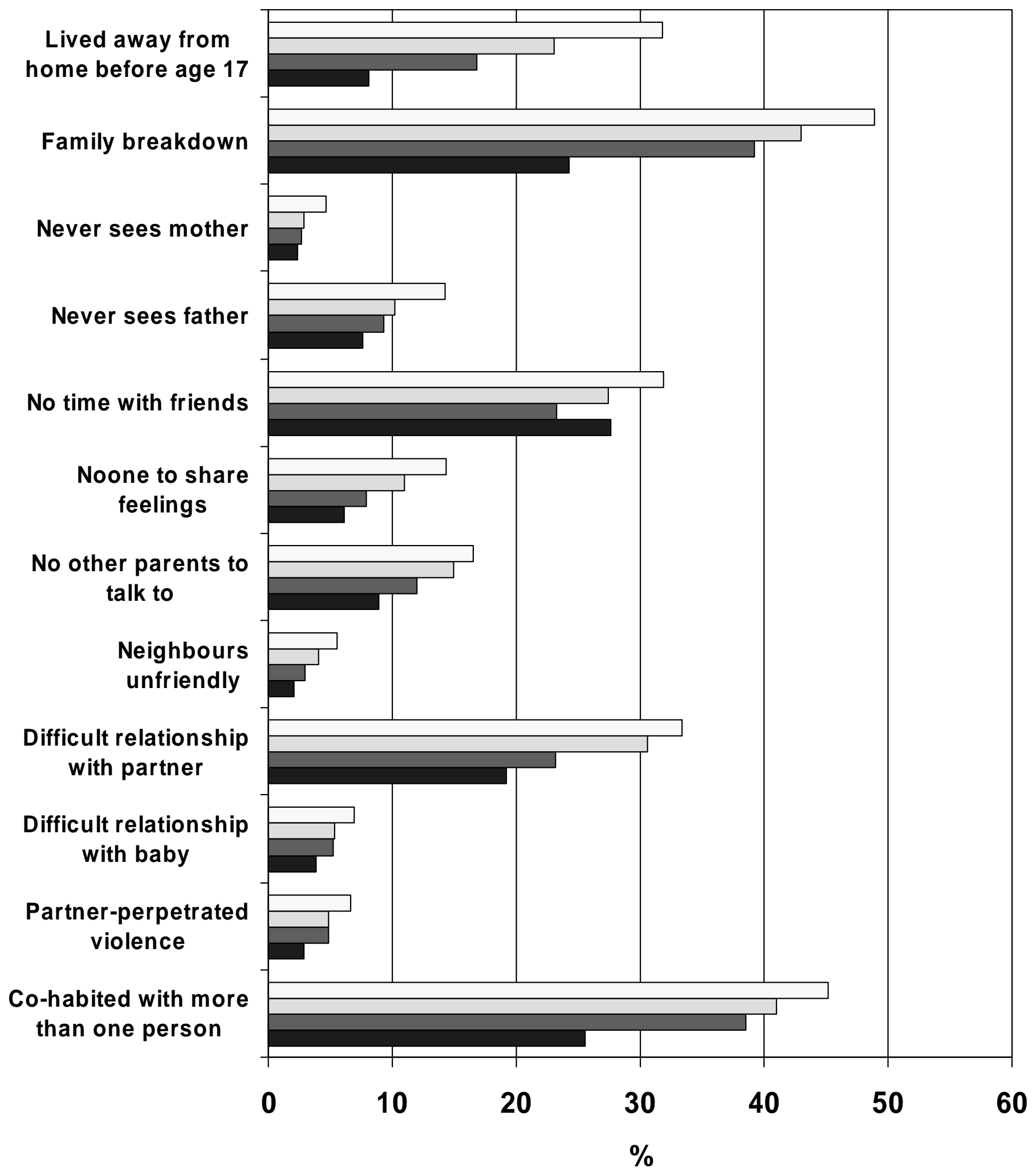

$\square$ Never $\square$ Quit $\square$ Light $\square$ Heavy 


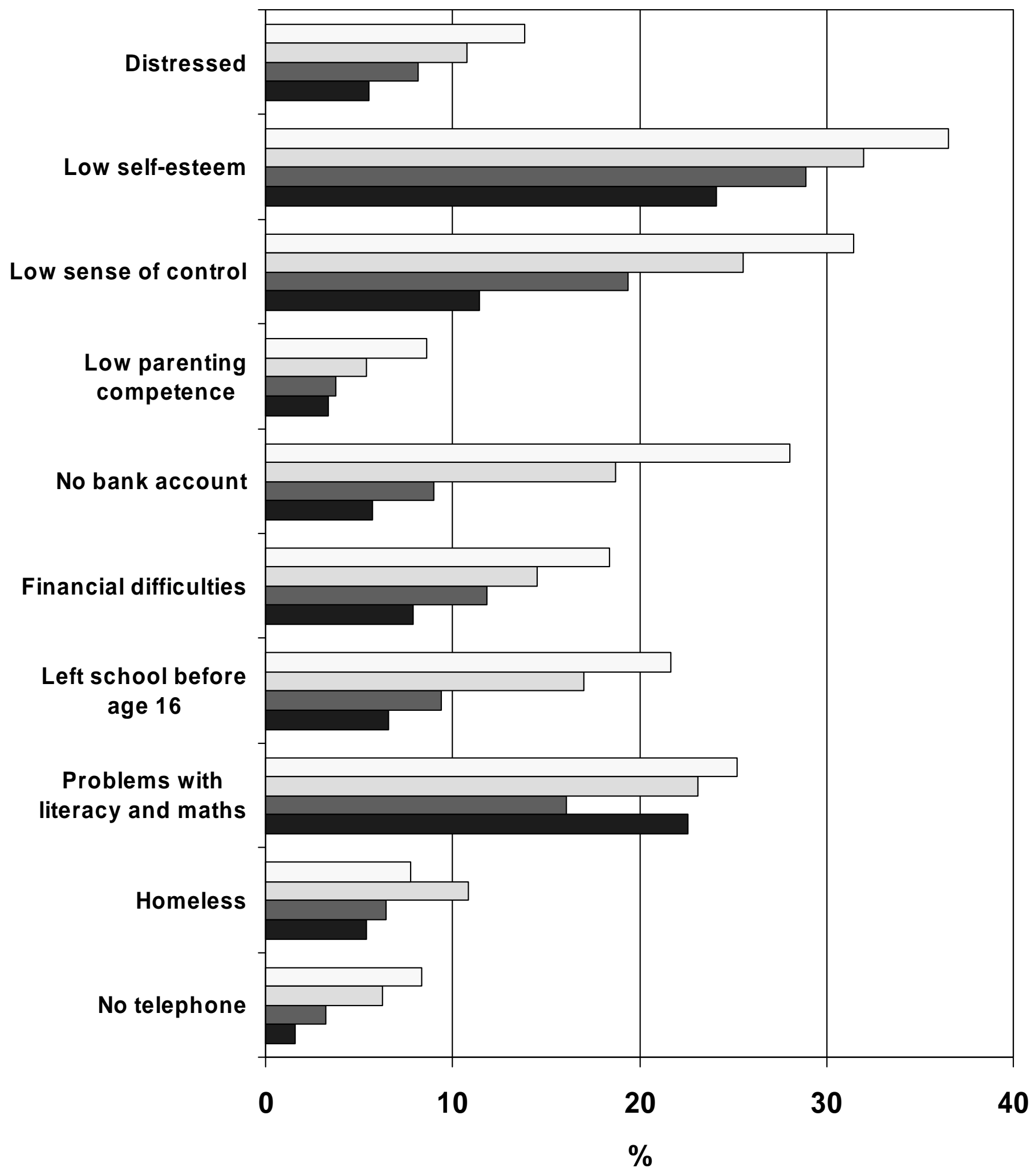

$\square$ Never $\square$ Quit $\square$ Light $\square$ Heavy 


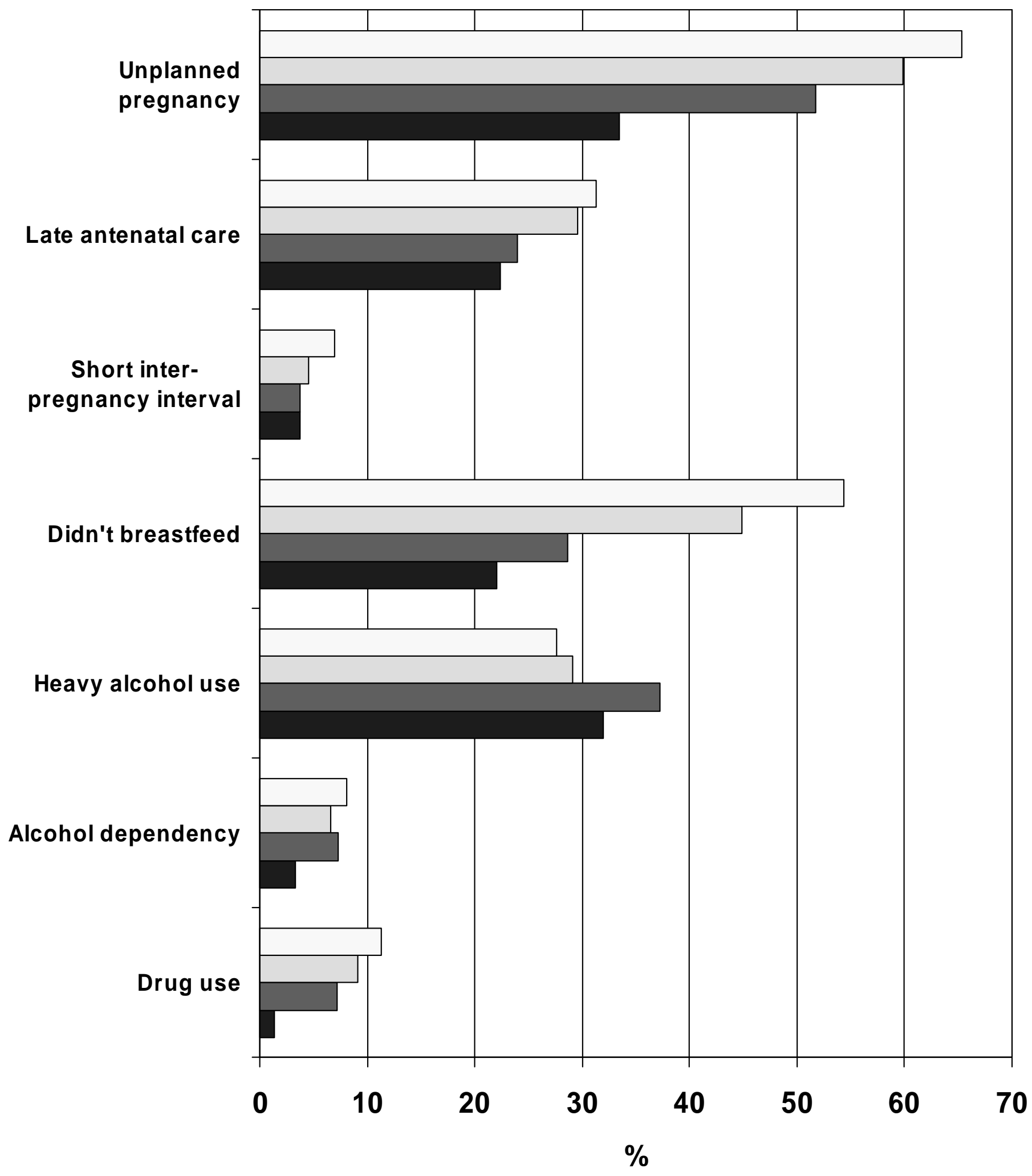

Never $\square$ Quit $\square$ Light $\square$ Heavy 